\title{
SISTEM INFORMASI PENGGAJIAN GURU PADA SMK RESPATI 1 JAKARTA
}

\author{
Musa Jaya $^{1}$, Lusi Ariyani ${ }^{2}$ \\ Program Studi Teknik Informatika, Fakultas Teknik dan Ilmu Komputer, \\ Universitas Indraprasta PGRI \\ Jalan Raya Tengah No 80, Kelurahan Gedong, Pasar Rebo, Jakarta Timur \\ musajaya.here@gmail.com ${ }^{1}$,lusiariyani0312@ gmail.com ${ }^{2}$
}

\begin{abstract}
Abstrak
Perkembangan revolusi industri 4.0 yang selalu berhubungan dengan perkembangan teknologi informasi dan komunikasi, diantaranya dunia digital, kecerdasan buatan dan sistem informasi yang terkomputerisasi mempengaruhi semua aspek kehidupan, salah satu yang terkena dampak perkembangan teknologi informasi adalah bidang pendidikan yaitu sekolah. Pada kajian ini, sistem penggajian untuk guru bertugas mencatat dan memproses data yang digunakan untuk membayar guru atas layanan yang telah mereka berikan. Tujuan penelitian ini adalah untuk merancang sebuah sistem informasi penggajian guru di SMK Respati 1 Jakarta. Metode penelitian yang digunakan adalah penelitian kualitatif dan pendekatan grounded theory. Hasil dari penelitian ini berupa sistem informasi yang dapat membantu sekolah dalam menerapkan sistem yang yang lebih baik, dapat mempermudah pekerjaan, meningkatkan kelancaran proses perhitungan gaji guru secara tepat, cepat dan akurat.
\end{abstract}

Kata Kunci: Sistem Informasi, Penggajian, Guru, Java

\begin{abstract}
The development of the industrial revolution 4.0 which is always related to the development of information and communication technology, including the digital world, artificial intelligence and computerized information systems affect all aspects of life, one of which is affected by the development of information technology is the field of education, namely schools. In this study, the payroll system for teachers is in charge of recording and processing the data used to pay teachers for the services they have provided. The purpose of this study was to design a teacher payroll information system at SMK Respati 1 Jakarta. The research method used is qualitative research and a grounded theory approach. The results of this study are in the form of an information system that can help schools implement a better system, which can simplify work, improve the smoothness of the process of calculating teacher salaries appropriately, quickly and accurately.
\end{abstract}

Keywords: Information Systems, Payroll, Teachers, Java

\section{PENDAHULUAN}

Perkembangan teknologi informasi saat ini dapat meningkatkan kualitas sumber daya manusia dalam menjalankan sistem yang sedang berlangsung, salah satu yang terkena dampaknya adalah bidang pendidikan yaitu sekolah. Sejalan dengan perkembangan teknologi maka sangat diperlukan suatu peralatan tertentu yang memiliki kemampuan, kemudahan, kecepatan dan memiliki kapasitas yang banyak dalam hal penyimpanan data (Firmansyah, 2008). Termasuk didalamnya sistem pengolahan data dan informasi yang tidak dapat begitu saja dipisahkan dengan kehidupan kita sehari-hari (Azizah, Mulyandi, \& Monica, 2013). Masalah-masalah pekerjaan seperti administrasi ataupun penggajian, manajemen sekolah yang baik tidak terlepas dari data-data yang banyak dan dapat berubah sewaktu-waktu, dalam hal ini adalah data guru, presensi dan penggajian guru yang mengajar di sekolah haruslah efektif dan efesien.Masalah penggajian termasuk masalah yang rumit, karena masalah ini tidak hanya menyangkut masalah jumlah rupiah yang diterima tetapi juga mempunyai implikasi yang sangat luas ditinjau dari sistem pengupahan dan kinerja (Sunarto, Rachmawati, \& Hilman, 2017).Sistem penggajian bertugas mencatat dan memproses data yang digunakan untuk membayar pegawai atas layanan yang mereka berikan (Saputra \& Bukhori, 2014). 
Gaji adalah suatu bentuk balas jasa ataupun penghargaan yang diberikan secara teratur kepada seorang pegawai atas jasa dan hasil kerjanya (Abdillah, 2013). Informasi merupakan salah satu kebutuhan di dalam setiap instansi (Purnamasari, 2013). Sistem informasi diciptakan agar berbagai macam proses manual dapat dikerjakan secara komputerisasi sehingga lebih efektif dan efisien (Moenir \& Yuliyanto, 2017). SMK Respati 1 Jakarta merupakan lembaga pendidikan yang sedang berkembang, pengolahan datanya masih dilakukan secara manual. Sistem penggajian yang masih manual sering menyebabkan kesalahan dalam perhitungan gaji dan membutuhkan waktu yang cukup lama dalam pencarian data. Berdasarkan alasan tersebut maka perlu mengadakan perubahan dari sistem sederhana menjadi sistem informasi yang terkomputerisasi, sehingga memberikan kemudahan, kecepatan dan keefektifan bagi pemakai dalam pengolahan data dan informasi khususnya dalam masalah penggajian.

\section{PENELITIAN RELEVAN}

Penelitian oleh Sunarto, Rachmawati dan Hilman (2017). Perancangan Sistem Informasi Penggajian Pada SMK Perintis 1 Depok. AMIK BSI Jakarta, 1(3), 195. Penerapan komputerisasi sistem penggajian mampu memecahkan permasalahan-permasalahan yang ada pada sekolah ini sehingga penggajian dapat berjalan lebih efektif dan efisien serta sistem penggajian guru yang sekarang lebih kondusif dibandingkan dengan sistem yang terdahulu.(Sunarto et al., 2017).

Penelitian oleh Kurniawan, Enggari dan Rani (2019).Perancangan Sistem Pengolahan Laporan Data Gaji Guru Basiskan Desktop Pada Sekolah SDN 06 Guguk Sarai Kab. Solok Dengan Menerapkan Bahasa Pemrograman Java dan Database Mysql.Dengan mengaplikasikan aplikasi penggajian guru berbasis desktop sebagai media teknologi, menjadikan proses penggajian guru dalam sekolah dilakukan secara lebih mudah, efisien dan interaktif antara guru dan bagian keuangan(Kurniawan, Enggari, \& Rani, 2019).

Penelitian relevan ini menjadi acun penting supaya mengenal tentang apa yang akan diteliti dan penelitian terdahulu ini sangat bermanfaat, yang membedakan penelitian ini dengan penelitian relevan adalah sistem yang dibuat lebih baik dalam penerapannya dan penggunaan lebih mudah dengan tampilan layar yang memudahkan pengguna, pehitungan mengenai penggajian juga terintegrasi dengan presensi guru dan jadwal guru.

\section{METODE PENELITIAN}

Penelitian yang digunakan adalah penelitian kualitatif dan pendekatan grounded theory karena kegiatan penelitian ini didasarkan pada ciri-ciri keilmuan yang rasional, empiris dan sistematis. Data yang diperoleh dari suatu penelitian merupakan data yang sesungguhnya terjadi pada objek penelitian dan data yang dikumpulkan oleh peneliti.

Metode pengumpulan data untuk mendukung penelitian ini sebagai berikut :

\section{Studi Pustaka}

Studi pustaka menjadi metode dalam pengumpulan berbagai sumber buku, artikel dan jurnal serta dokumen yang berkaitan dengan penelitian.

\section{Survei}

Untuk mengetahui dan memperoleh data primer yang diperlukan di SMK Respati 1 Jakarta, secara langsung mengamati proses yang dilakukan pada proses penggajian guru dan sekaligus mengumpulkan data dan keterangan-keterangan yang akan digunakan dalam penelitian.

\section{Wawancara}

Wawancara dilakukan di SMK Respati 1 Jakarta dengan didampingi oleh ibu Eka Savhira, S.Kom. dan ibu Ayu Puspa Lestari, S.Pd. mengenai penggajian guru. Data yang dikumpulkan melalui wawancara ini akan digunakan sebagai data-data pendukung dari fakta-fakta yang telah ditemukan pada survei secara langsung, sehingga pemaparan hasil penelitian dapat dijelaskan secara lebih mendalam. 


\section{HASIL DAN PEMBAHASAN}

Pengolahan data mengenai penggajian harus tersimpan dengan baik, sehingga dapat digunakan dengan mudah untuk diolah menjadi informasi. Peranan sistem penggajian sangatlah penting, maka perancangan harus dilakukan dengan baik agar dapat memberikan layanan dan dapat membantu memberikan dukungan informasi bagi pihak manajemen, dapat berupa informasi yang berkualitas yang disajikan dalam bentuk laporan.

Aturan bisnis sistem yang diusulkan :

1. Tata usaha input data guru dan menyimpan data tersebut ke dalam database Guru, yang kemudian tata usaha mengelola data tersebut untuk kepentingan adminstrasi dan dapat melihat kembali data guru untuk keperluan arsip ataupun laporan.

2. Tata usaha input jadwal guru dan menyimpan data tersebut ke dalam database Jadwal, yang kemudian memberikan jadwal guru kepada guru yang bersangkutan.

3. Guru input presensi KBM dan menyimpan data tersebut ke dalam database Presensi_KBM. Untuk guru piket input presensi piket dan menyimpan data tersebut ke dalam database Presensi_Piket. Tata usaha mengelola data tersebut yang kemudian dilaporkan ke bagian keuangan untuk penggajian.

4. Bagain keuangan input gaji guru dan menyimpan data tersebut ke dalam database Slip_Gaji. Untuk tabungan, bagian keuangan input tabungan dan menyimpan data tersebut ke dalam database Tabungan. Bagian keuangan mengelola data penggajian tersebut, memberikan slip gaji dan tabungan guru serta membuat laporan penggajian guru.

5. Tata usaha mencetak laporan data guru, laporan jadwal guru, laporan presensi KBM dan laporan presensi piket. Adapun bagian keuangan mencetak slip gaji, tabungan guru dan laporan penggajian guru.

Rancangan sistem yang diusulkan:

Diagram Alir Data adalah penggambaran dari aliran data di dalam sebuah sistem atau proses. Selain itu DAD menampilkan inputan dan keluaran yang terjadi antara entitas dan sistem itu sendiri (Subianto, 2020). Berikut merupakan diagram alir data yang diusulkan untuk sistem informasi penggajian guru pada SMK Respati 1 Jakarta :

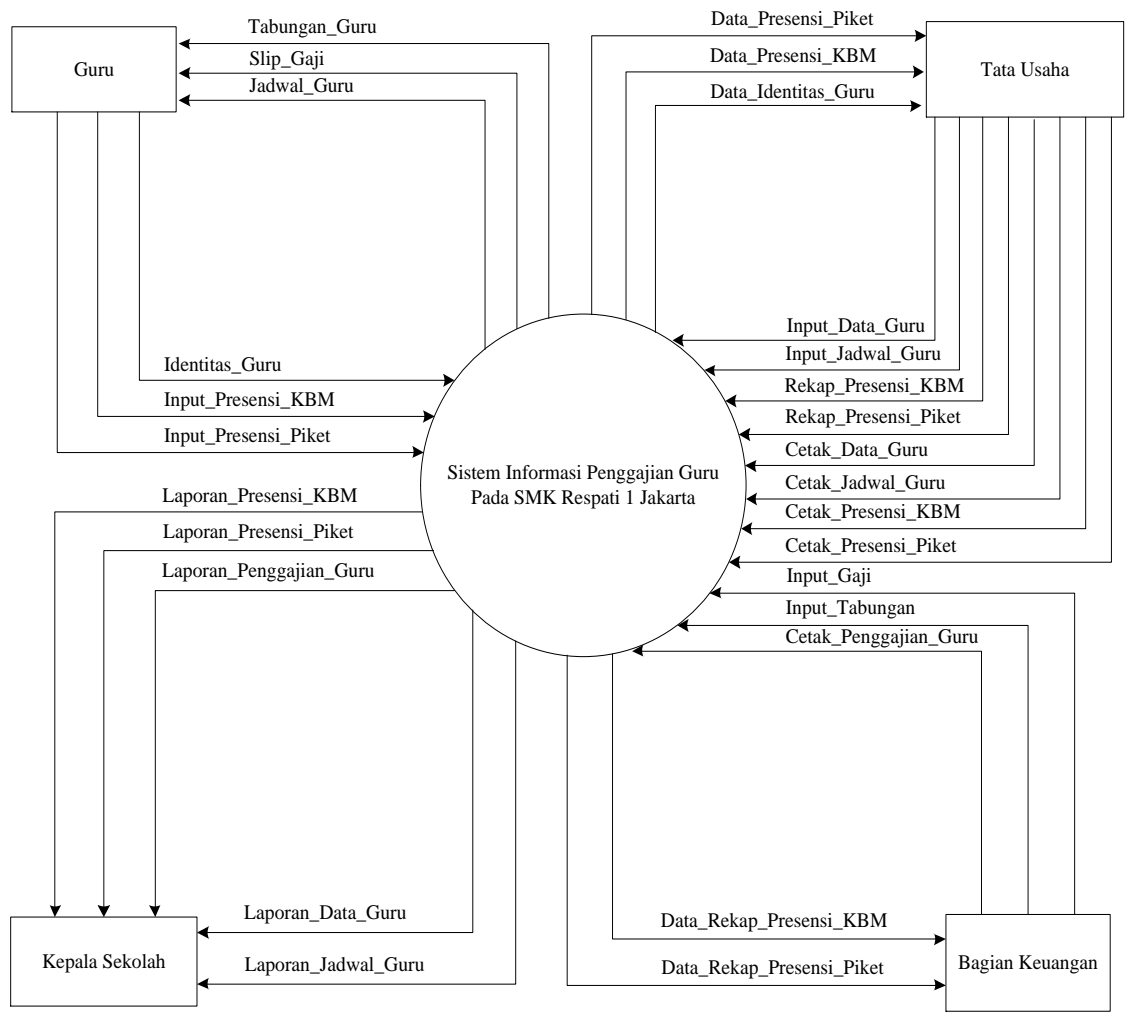

Gambar 1. Diagram Alir Data (DAD) 
Diagram alir data untuk sistem informasi penggajian guru dengan arus mengenai data masukan, proses dan keluaran sistem.

Entity relationship diagram (ERD) adalah suatu diagram dalam bentuk gambar atau simbol yang mengidentifikasi tipe dari entitas di dalam suatu sistem yang diuraikan dalam data dengan atributnya, dan menjelaskan hubungan atau relasi diantara entitas tersebut (Fitra et al., 2018).

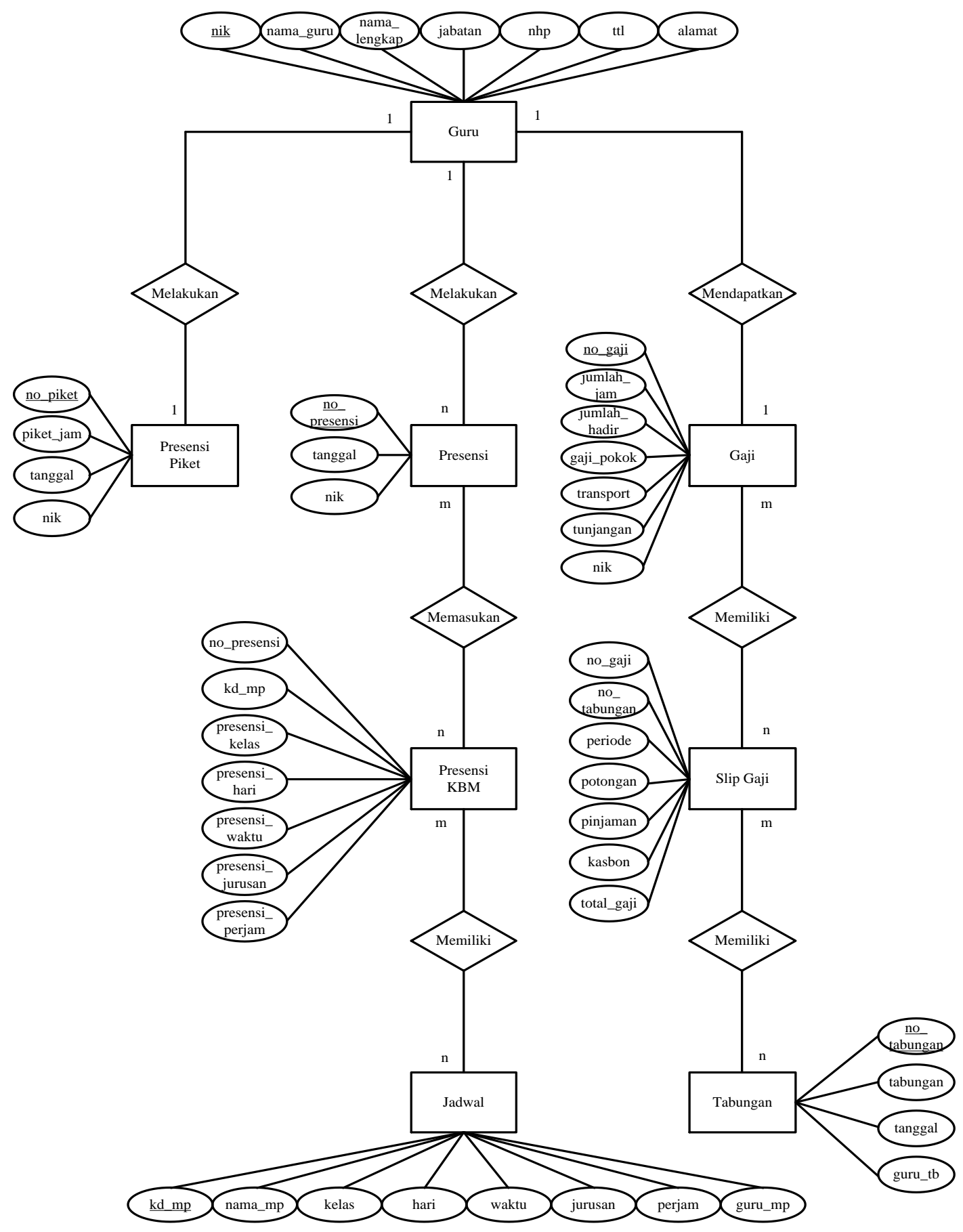

Gambar 2. Entity Relationship Diagram

Hubungan relasi antara entitas pada basis data sistem informasi penggajian guru untuk rancangan basis data yang diusulkan. 
Tampilan layar sistem informasi penggajian guru :

\section{Menu Utama Guru}

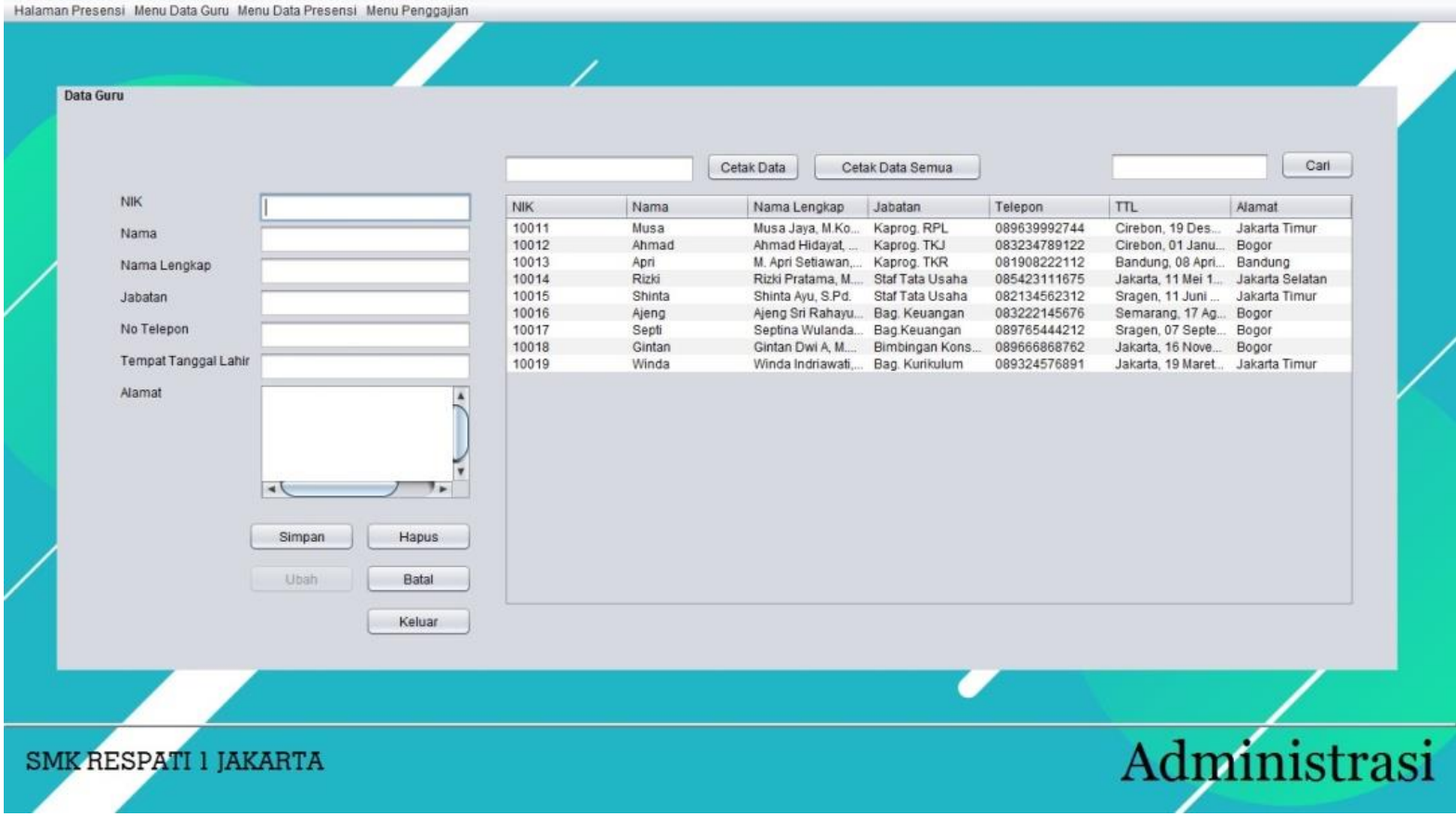

Gambar 3. Menu Utama Guru

Pada menu utama guru, guru yang memiliki hak akses dapat mengakses menu halaman presensi, menu data guru, menu data presensi dan menu penggajian.

\section{Form Presensi KBM}

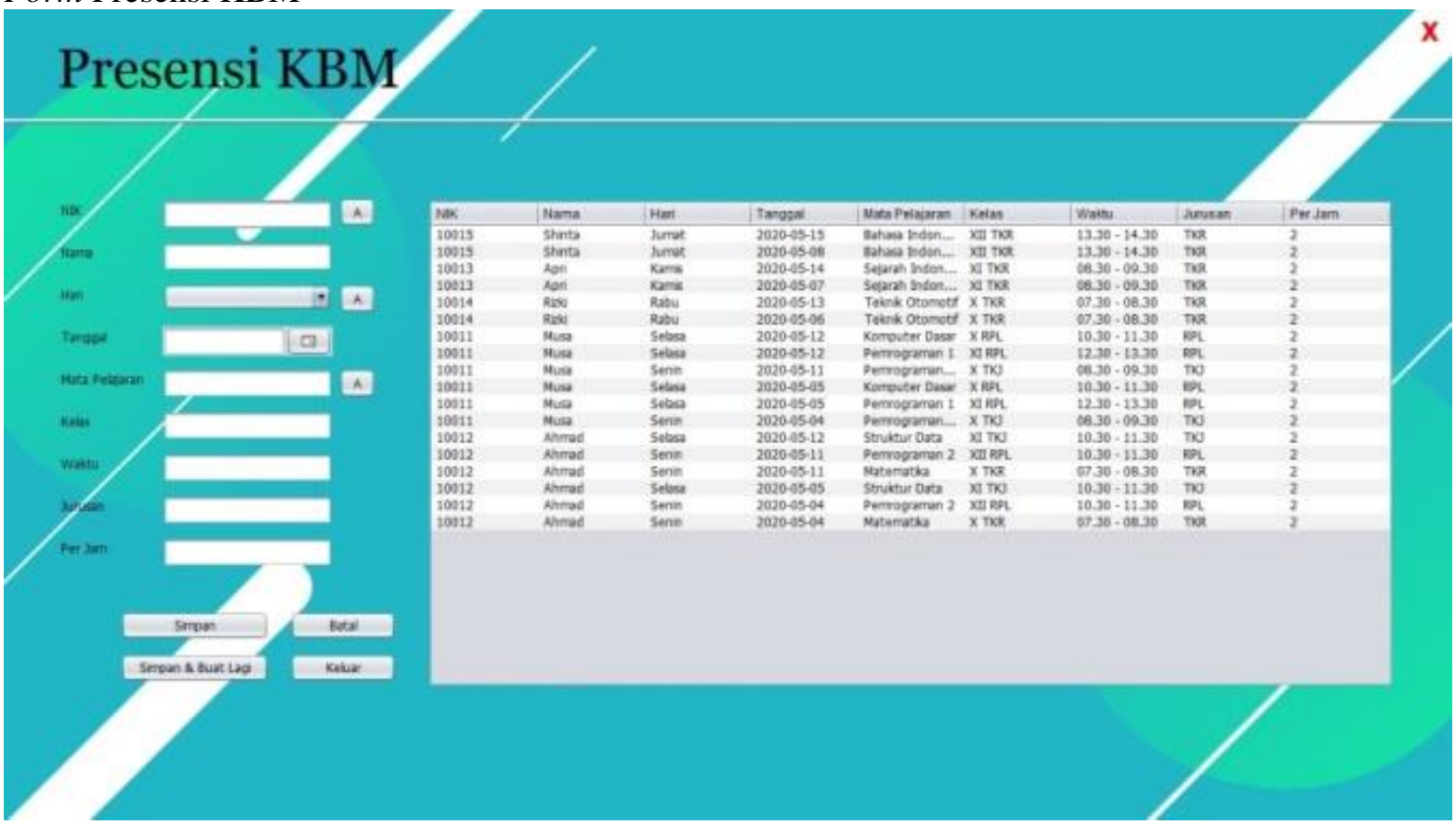

Gambar 4. Form Presensi KBM

Tampilan form ini dapat diakses oleh guru yang memiliki hak akses untuk melakukan presensi KBM dengan mengisi nik, nama, hari, tanggal, mata pelajaran, kelas, waktu, jurusan dan per jam. 
Form Presensi Piket

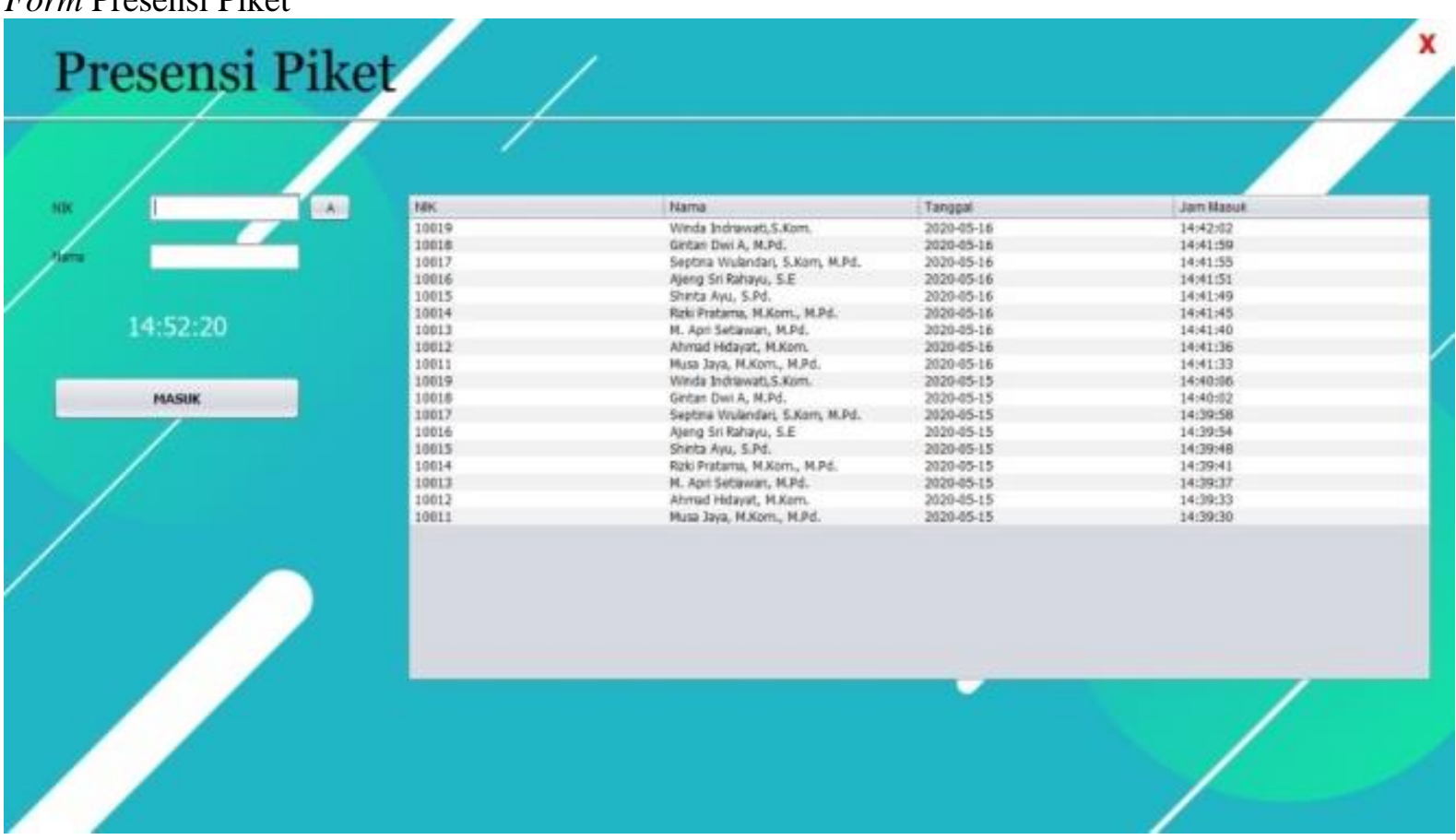

Gambar 5. Form Presensi Piket

Tampilan form presensi piket ini dapat diakses oleh guru yang memiliki hak akses untuk melakukan presensi piket dengan mengisi nik dan nama. Terdapat jam real time yang berfungsi sebagai tanda kehadiran guru piket.

\section{Form Penggajian Guru}

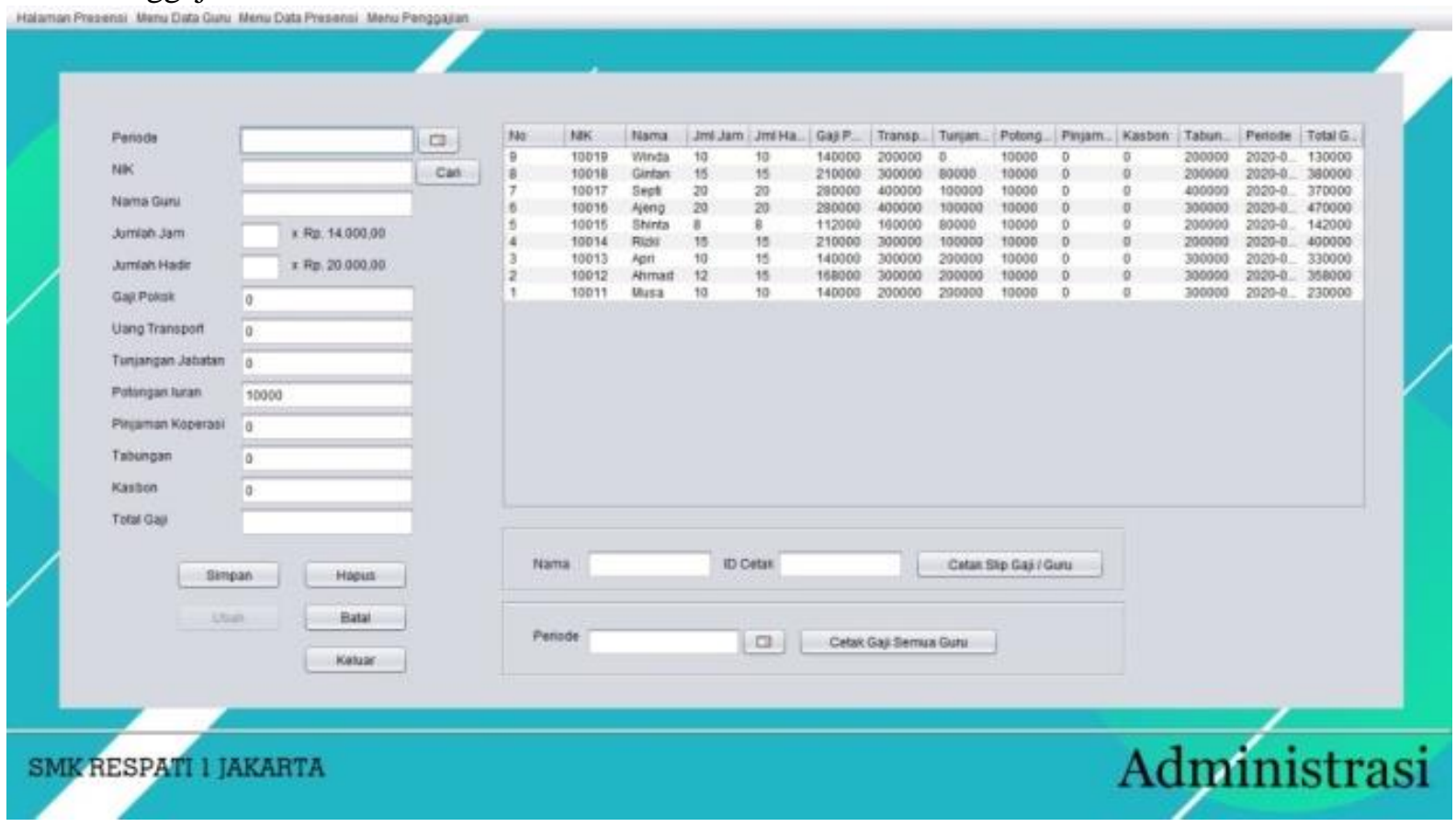

Gambar 6. Form Penggjian Guru

Tampilan form penggajian guru dapat digunakan oleh guru yang memiliki hak akses sebagai admin untuk mengelola penggajian guru dengan mengisi periode, nik, nama guru, jumlah jam, jumlah 
hadir, gaji pokok, uang transport, tunjangan jabatan, potongan iuran, pinjaman koperasi, tabungan, kasbon dan total gaji.

Laporan Penggajian Guru

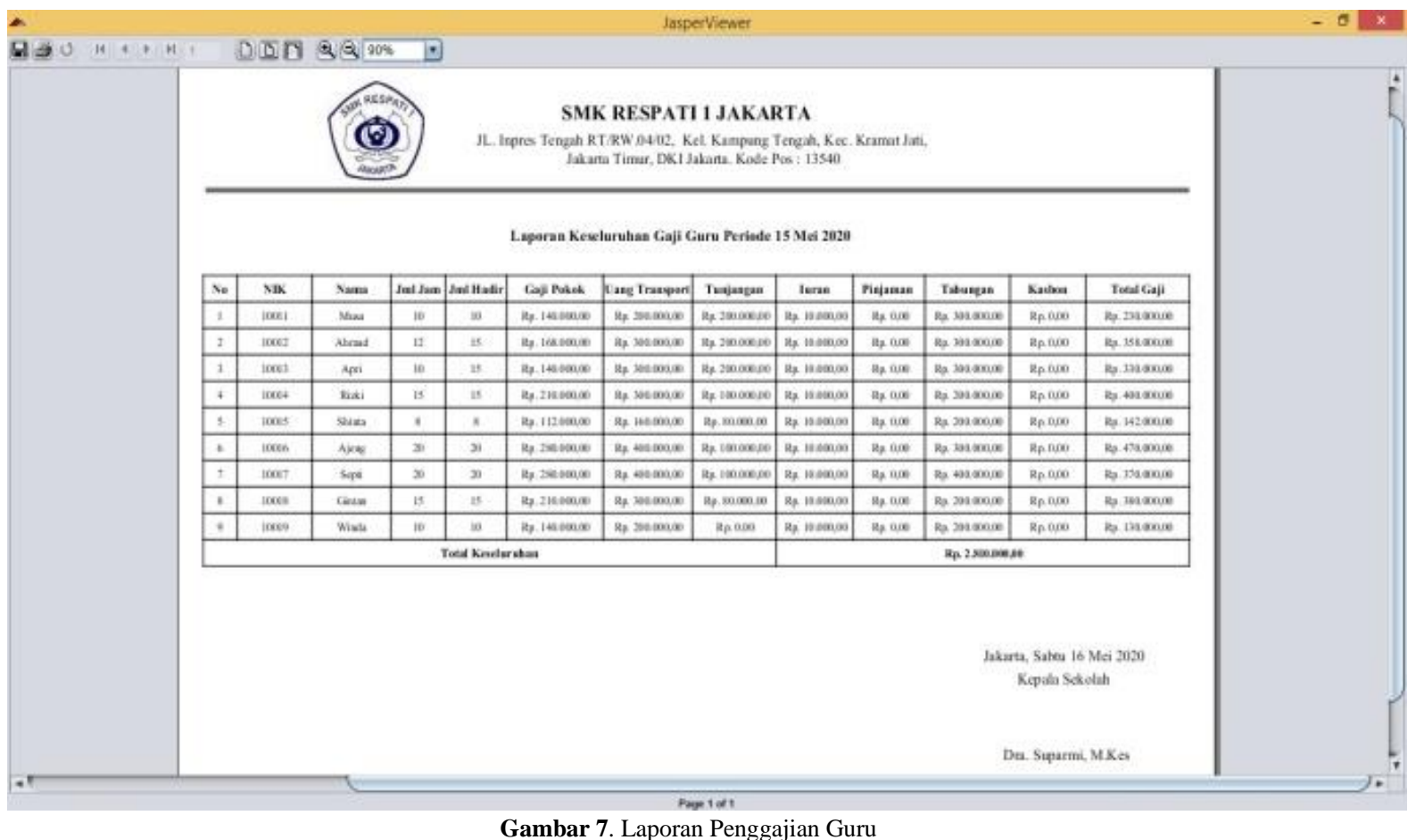

Gambar 7. Laporan Penggajian Guru

Tampilan laporan gaji guru yang berisikan keseluruhan data gaji guru berdasarkan dari satu periode, hasil cetak gaji semua guru dari tampilan layar form penggajian guru.

\section{SIMPULAN}

Revolusi industri 4.0 mengharuskan sekolah menerapkan sebuah sistem berbasis teknologi dan informasi, dengan dibuatnya rancang bangun sistem informasi penggajian guru pada SMK Respati 1 Jakarta berbasis Java, maka pengolahan data berupa data guru, jadwal guru, presensi guru, dan penggajian guru bisa berjalan dengan lebih baik. Sistem informasi yang terkomputerisasi dapat mempermudah pekerjaan, meningkatkan kelancaran proses perhitungan gaji guru, memberikan data secara tepat, cepat dan akurat sehingga lebih mudah dalam penyampaian laporan yang dibutuhkan oleh kepala sekolah.

\section{DAFTAR PUSTAKA}

Abdillah, L. A. (2013). Perancangan basisdata sistem informasi penggajian. 135-152. Retrieved from http://arxiv.org/abs/1302.0337

Azizah, N., Mulyandi, R., \& Monica. (2013). Penggajian Guru Berbasis Web Pada Sma. 147-158.

Firmansyah, R. (2008). Rancang Bangun Sistem Informasi Penggajian Studi Kasus : Smk Kesehatan Harapan Indonesia 3. 230-236.

Fitra, K., Miten, J., Informasi, S., Sarjana, P., Dinamika Bangsa, S., Jendral, J. J., \& Thehok -Jambi, S. (2018). Analisis Dan Perancangan Sistem Informasi Penggajian Karyawan Pada Radio Republik Indonesia ( Rri ) Jambi. Jurnal Manajemen Sistem Informasi, 3(2), 1083-1092.

Kurniawan, A., Enggari, S., \& Rani, L. N. (2019). Perancangan Sistem Pengolahan Laporan Data Gaji Guru Basiskan Desktop Pada Sekolah Sdn 06 Guguk Sarai Kab. Solok Dengan Menerapkan Bahasa Pemrograman Java Dan Database Mysql. UPI YPTK Jurnal EKOBISTEK, 1(1), 1-18.

Moenir, A., \& Yuliyanto, F. (2017). Perancangan Sistem Informasi Penggajian Berbasis Web dengan Metode Waterfall pada PT. Sinar Metrindo Perkasa (Simetri). Jurnal Informatika Universitas Pamulang, 2(3), 127. https://doi.org/10.32493/informatika.v2i3.1237

Purnamasari, T. (2013). Pembangunan Sistem Informasi Pengolahan Data Pegawai Dan Penggajian Pada Unit Pelaksana Teknis Taman Kanak-Kanak Dan Sekolah Dasar Kecamatan Pringkuku. Jurnal Speed - Sentra Penelitian Engineering Dan Edukasi, $\quad 5(2), \quad 1-6 . \quad$ Retrieved from http://www.ijns.org/journal/index.php/speed/article/view/1100 
Jurnal Riset dan Aplikasi Mahasiswa Informatika (JRAMI)

Vol QZ No Q2 Tahun ZOZI

e-ISSN : 2715-8756

Saputra, A. W., \& Bukhori, I. (2014). Perancangan sistem informasi penggajian Pada Sekolah Menengah pertama (SMP) PGRI Kebonagung. Indonesian Journal on Networking and Security, 3(3), 6-10.

Subianto. (2020). Penerapan Metode Rapid Application Development dalam Perancangan Sistem Informasi Pendataan. XVI(1), 46-55.

Sunarto, Rachmawati, S., \& Hilman, S. (2017). Perancangan Sistem Informasi Penggajian Pada SMK Perintis 1 Depok. AMIK BSI Jakarta, l(3), 195 